\title{
Unveiling Hidden Social Design: New Roles for Sociologists
}

\author{
Ph.D. Professor Lubomir POPOV ${ }^{1}$ \\ Ph.D. Associate Professor Gary DAVID ${ }^{2}$ \\ ${ }^{I}$ School of Family and Consumer Sciences, American Culture Studies affiliated faculty, Bowling Green State \\ University \\ ${ }^{2}$ Bentley University \\ (C) 2017 Lubomir Popov, Gary David \\ This is an open access article distributed under the Creative Commons Attribution-NonCommercial-NoDerivs license \\ (http://creativecommons.org/licenses/by-nc-nd/3.0/) \\ DOI: 10.1515/eras-2017-0001
}

\begin{abstract}
This paper will help foster a more favourable attitude to professional involvement in social design projects and highlight new areas of professional opportunity for sociologists. To overcome the psychological barriers to design engagement and to foster motivation for social design, the authors discuss a case of social design decision making by non-sociologists. The methodology is informed by Activity Theory and Design Theory, and the approach adopted is based on analyzing current best practices, departing from conventional and customary practices. The authors discuss the Fun Palace, which was an innovative architectural project in the 1960s Great Britain, conceived with a fundamental social aim of providing life-long education and professional retooling to working class people in a relaxed and entertaining environment. The paper highlights the sociological nature of decision making in the planning phase of the project as well as the need for sociological knowledge and skills. The explication of the social design activities in the Fun Palace project can inspire sociological practitioners with ideas about entering into various industries and, in particular, in the design of social organizations and buildings.
\end{abstract}

Keywords: social design, sociological practice, sociological careers

\section{Introduction}

Sociologists have a unique set of knowledge and skills to assist in bringing positive changes in society. They are the people who know most about how society works, what the mechanisms of social functioning are, and how to change undesirable social phenomena and situations into desirable ones. Sociologists are enthusiastic about changing society for the better and resolving social problems. They are engaged social scientists and leaders. However, based on our observations and research, sociologists hesitate to engage in formal project work that leads to social change. For many sociologists, such engagements are tantamount to social design, engineering and service to the institutions that promulgate inequality and oppression, distrusting any attempt to introduce the practice as a professional activity. Their attitudes are shaped by distrust of the political establishment, the dominant power structures, and the institutionalized forms of participation in governance and social change.

Here, it is important to keep in mind that social design is only an instrument, a tool. The outcomes depend on the people who use this instrument in a manner guided by their ethics, values, and goals. There are a number of cases where social design has been used for the good of the public. These cases need more attention. Only a careful analysis of the conditions and circumstances that foster such positive results can emancipate social design.

Another psychological barrier to engaging in social design is the lack of information about the nature and structure of the (social) design process, the technicalities of applying sociological knowledge in practical situations, and the psychological barrier of getting into a new area of operation. In their course of study, sociologists undergo extensive preparation in 
research methods, but never or rarely in design methods. Thus, sociologists are confident researchers who they hesitate to engage in social design projects and engineering.

The intent of this paper is to nurture a more favourable attitude toward professional involvement in social design projects, to break the psychological barriers to design engagement, to foster motivation for social design, and to highlight a new area of professional opportunities for sociologists. In order to achieve this, we introduce sociologists to social design decision making by non-sociologists, and unveil and explicate the decision-making process and the extent of sociology-related decision making. Therefore, we discuss The Fun Palace, an innovative and exceptional architectural project that is tantamount to social design, but was executed by non-sociologists.

The presentation of the project and its discussion are simply tools for achieving the goals of the paper rather than a critique of the project and the participants. Thus, many sociologists will see design decisions that they would have handled differently. Yet, perhaps they will get inspiration for similar endeavours. We also believe that by explicating the social design process, we can provide sociological practitioners with ideas about entering and operating into other professional fields and, in particular, in the design of social organizations and buildings.

We would like to emphasize that this is not a paper about the Fun Palace project or its history, nor is it a theoretical discussion on the process of architectural or social design. We use the Fun Palace project as empirical material to illustrate the multitude of decisions in architectural design that are social and sociological by nature, rather than architectural. We want to highlight a specific case where, because of lack of sociological initiative and involvement, non-sociologists took leadership and engaged courageously in social design and engineering, making decisions that very often were outside the scope of their professional preparation and expertise. We hope that highlighting such a case will motivate many sociologists to specialize in a number of industries where they can make a change with their sociological imagination (Mills, 1959).

\section{Conceptual and Methodological Foundations}

\subsection{About Social Design}

According to sociologist Robert Boguslaw (1971), social design is an activity for introducing order into future social situations, "having as its primary consequence the specification of a range of alternatives for channeling social behavior" (p. 256).He calls "social designers" all people who engage in such activities, whetherthey think of themselves in these terms or not, although "many, probably most of them, are not social scientists" (p.241). Boguslaw(1971)treats all sociologists who use the design perspective as "deliberate social designers" (p. 257) who are inevitably involved in social action on some level. Sociologists who engage in social action are "doers" as scientists/engineers. He is convinced that social design is implicit in contemporary social decision-making.

Design is an activity generating new morphological representations that will be used as guides in the process of implementation. Social design is about organizing social morphology in a new way in order to achieve particular goals. Durkheim (1960/1912) discussed how social morphology referred to the structure of social relationships. This also is extended by Rawls (2004) to include the "material" of social entities, processes, and other phenomena. Since the person does not exist apart from society, but rather isaproduct of 
society, it would then make sense that changes to the environment would result in changes in individuals and the relationships between them. By affecting the context in which human relationships take place,social design provides new solutions to social problems, proposes models for social change, and produces blueprints for achieving social objectives (Armstrong et al., 2014; Koskinen \& Hush, 2016). Blueprints present a desired and possible future state of social organisms, processes, and behavior systems. This is accomplished by developing new connections, relations, and interactions between components and subsystems.

\subsection{Methodological Foundations}

Our analysis is informed and guided by both activity theory and design theory. Activity Theory (Chaiklin et al., 1999; Engeström et al., 1999; Kaptelinin \& Nardi, 2006; Lektorsky, 1990; Leont'ev, 1978) is a major instrument that guides both the interpretation of design processes and the activity content of the project. The Activity Theory approach has been successfully applied for several decades within the fields of education and human development, human-computer interaction, collaborative work structures, and organizational design. This approach is productive for analyzing the social world in terms of problems, objectives, and activity systems, as well as agency and decision making. This approach has demonstrated strong investigative potential and has proven to be very productive in design situations. It works well for studying institutions in respect to context, social functions, and structures. Social organizations are analyzed for their mission, objectives, and activity systems or operations. From this perspective, social design is about new social processes and activities, new behavioural patterns, and new ways of doing things. In this respect, Activity Theory is productive in analyzing and interpreting both the content part of the social design project and the articulation of the social design activities.

Design Theory provides an overall framework for seeing the world in a proactive way, envisioning problems, tasks, and solutions, as well as methods of meeting goals and sequences of procedural steps that lead to solutions. There are many perspectives on, and definitions of, design. Design theory is a field of its own. Design is a planned change-a creative leap into the future; design is about making decisions and finding solutions. From a project management perspective, professionals talk about several phases, such as planning/programming, schematic design, design development, construction documents, and so forth. In reality, the intangible processes of creation must be organized in phases so that there is an opportunity for evaluating each step towards the completion of the (material) artefact. In this study, Design Theory provides an analytical perspective and a general framework for discussing the Fun Palace project. We have adopted a process framework that involves analysis of the project situation, problem formulation (Peña, 2012), generating a design concept, and developing the design concept.

Our approach is based on current best practices rather than on conventional and customary practices. These extraordinary and exceptional cases bring fresh insights and new understandings. In other words, our search is not for what is predominant, typical, or representative. This methodological attitude reflects an affinity toward exploring new phenomena that can carry the project genotype of the future. We have searched out information-rich cases and their intellectual appropriation. Thus, this is an extreme case analysis that will serve as a magnifying glass for inspectingthe hidden structures of future practices. 


\subsection{The Case: Fun Palace}

In this paper, we use the Fun Palace project as empirical material for analysis and discussion. The Fun Palace project is well documented, and there are a number of publications about it within the realms of history of architecture, theatre, mass media, and cybernetics (Holdsworth, 2011; Lobsinger, 2000; Mathews, 2007a). In all of these fields, the project is discussed from different perspectives, thereby accommodating different professional interests. This availability of information is one more reason to take Fun Palace as a case for discussing social design. Furthermore, this project has not yet been analyzed in sociological publications, at least not with the purpose of highlighting the nature and process of social design endeavors.

Another reason to select the Fun Palace project for this study is the fact that it was initiated and developed by prominent British avant-garde intellectuals who volunteered to work as an informal interdisciplinary team (Mathews, 2007a; Mathews, 2007b). They came from different professional backgrounds but were united by their motivation to work on a social problem they perceived as both crucial and urgent for the nation. They were recruited because at that time there were no institutionalized professionals to provide the knowledge and skills sought by the leaders of the project. The leadership was provided by nonsociologists: Joan Littlewood (theatre), Gordon Price (architecture), and Gordon Pask (cybernetics). Although there were several sociologists involved, they were not among the leaders of the project and had a very low profile in this endeavour. This is one more reason to discuss this case and the opportunities for sociologists.

The project continued for about ten years and was terminated at the stage of preliminary sketches and site selection (Mathews, 2007a). However, the part of the project that envisaged the social organism that would function in the new building was quite well developed. It alone can be treated as a social design project. This part is our primary interest because it illustrates very well how spontaneous social design happens, the social nature of decision making, and the opportunities for professional sociologists to contribute their knowledge and skill set. Thus in this paper, we will focus on the social component of the Fun Palace project rather than on its architecture or its place in the history of avant-garde theatre.

\section{The Fun Palace as a Social Design Project: Process and Decision Making}

In this section of the paper we discuss the Fun Palace project with the intent to showcase the design process, the social nature of decision making during the initial stages of the project, as well as the opportunities for sociologists. We have analyzed the case and formatted the presentation following the design process framework that we adopted (analysis of the project situation, problematization of the project situation, formulation of the problem, generating a concept, developing the concept). Our intent is to inform sociologists about the scope of sociological engagement in such projects; to provide them with information about the process and their eventual role in such cases, and to foster motivation to search for similar projects and take a leadership role.

\subsection{Analyzing the Social Situation: The Social Context of the Fun Palace Project}

The 1950s brought tremendous change to Britain. The empire was crumbling. Economic growth was much slower than societal expectations. Lack of cheap resources from the colonies and lack of interest in technological updating made heavy industry uncompetitive. The comparative technological lag, the new market conditions, and foreign 
competition was negatively impacting British manufacturing. The unemployment rate grew tremendously; the restructuring of industry made large numbers of workers whose skills were not needed any more obsolete. At the same time, industry could not find enough qualified workers for newly emerging tasks and positions (Mathews, 2007a).

Since, British society was changing at a pace that working class people could not withstand, the nation's values system started changing and even crumbling. The country was facing both accelerated cultural change and cultural anarchy. The educational system became inadequate. It suffered from inaccessibility, a lack of opportunities for personal development, and inability to support desired social mobility (Holdsworth, 2011; Mathews, 2007a). Furthermore, British industry was not catching up with the many newly emerging technological phenomena: factory automation, the first computers, and promises for digital information processing. Instead of alleviating the social problems in Britain, these new phenomena were contributing to structural unemployment and associated issues (Holdsworth, 2011; Mathews, 2007a).

In this time of rapid transformation, the working class suffered most. Sweeping social and cultural changes confused people and led to loss of meaning of life. The promises for a welfare state were not fulfilled in the expected. The structural unemployment had a smashing effect on people who knew that jobs existed, but they could not fill them because of the lack of their knowledge and skills (Holdsworth, 2011; Mathews, 2007a).

This sense of powerlessness was further fuelled by overly optimistic forecasts that machines would take over the manufacturing processes and make people redundant. There were predictions that by the year 2000, the work week would be reduced to 20 or even 15 hours (Carey, 2000, p. xi) and people would have an abundance of leisure time. However, many current workers had too much free time already because they were unemployed. Leisure became a major issue for discussion, rivalling unemployment and education.

In this social situation, the famous theatre director Joan Littlewood initiated the development of a completely new type of theatre building that would reflect her visions about vanguard theatre performances. Littlewood invited iconoclastic architect Cedric Price (Holdsworth, 2011; Mathews, 2007a) to work on the design. Price took the idea and overhauled it (Mathews, 2007a; Mathews, 2007b; Price, 2003), thus fostering the emergence of a different project that was called The Fun Palace. Price and Littlewood found common philosophical ground and together transformed the initial request for a theatre building into a facility of a completely new type. Together they designed a new social organization that fused the realms of performance and entertainment with learning, personal growth, and human development (Littlewood, 1964; Price \& Littlewood, 1968). Ultimately, the theatre component became only a small part of the whole endeavour.

\subsection{Problematizing the Social Situation}

The second step in the design process is to problematize a social situation that evidently is not satisfactory (Peña, 2012). This is a process of clarifying the nature of dissatisfaction, how important this phenomenon is for the future of society, and what can be the negative consequences from it. Only after this stage is completed it is prudent to conceptualize the actual problem and to develop it in detail. These steps create a solid foundation to the search for a design solution.

The downturn of British industry and the variety of its effects on British society attracted the attention and creative efforts of various groups of intellectuals. In the ensuing debate in British society, several topics emerged. For example, Morris Carstairs, a psychiatrist, talked about the effects of the fast-paced socio-cultural change on British society (Mathews, 2007a, p. 12). He was concerned with the psychological fallout from the economic 
situation, and also with the ensuing effects on national identity, and moral and mental health. Carstairs suggested that the major reasons for this crisis was the inadequate education, deteriorating motivation for life-long education and personal growth, and a lack of preparation by the majority of the population to face social and cultural change. He proposed to overhaul the education system as a major instrument for developing innate abilities, new ways of thinking and learning, and new professional skills.

Structural unemployment and the advent of automation led to predictions of steady growth of the number of people who were out of work, as well as those who worked part-time and in a very short work week. This in turn led to several other concerns. One was the increase in leisure time and its effects on working class people, both positive and negative; another was the debilitating effects of unemployment. A number of intellectuals became concerned with the pace and scale of change and its psychological and moral effects on the general population's state of mind. There were predictions about increased levels of mental health problems and social deviance as people lost their meaning of life, self-esteem, and hope in a better future (Holdsworth, 2011, p. 210; Mathews, 2007a, p. 12, p. 69, p. 197; Wiener, 1981).

Some intellectuals were warning that these phenomena had already started and were developing at a rapid pace. Artists and intellectuals in this period started seeing tendencies toward dehumanization in everyday life, as well as a lack of motivation, moral degradation, and aggression expressed at unprecedented levels. Unemployment and tedious manual work led to passivity and inertia, as well as to violent expressions of outrage at the lack of meaningful prospects.

In the case of the Fun Palace project, the problematization of the social situation was done at several levels. First, there was the level of spontaneous societal discussions. Second, Joan Littlewood had been reflecting on these issues for a long time. And third, the social situation was a subject of discussion by the Fun Palace team members in the initial stages of the project. This discussion created the foundation of their problem-solving process and the decisions they made. For example, Joan Littlewood and her team saw the breaking down of the centuries-old dichotomy of work and leisure. They were optimistic at the prospect that meaningful leisure would prevail in people's lives. They envisaged leisure as a way to empower working class people, to provide them with time for learning and education, to boost their creativity, and to motivate them toward productive and meaningful living (Holdsworth, 2011; Mathews, 2007a).

\subsection{Formulating the Project Problem}

Philosophers of science and technology claim that the formulation of the problem is the most important part of a project. If the problem is not formulated correctly, any ensuing design solution might go wrong. The problem formulation provides direction and guidance in the future design acts, the formulation of sub-problems and tasks, and the evaluation of design outcomes. The task of problem formulation can be envisaged in a number of ways, ranging from a short description to an expanded study that includes general needs, goals and objectives, priorities, and design requirements (Peña, 2012). This step takes different formats in different design fields, has different names, and delivers a range of products of this class. However, the common denominator of all is the conceptualization of a problem that needs to be resolved.

Joan Littlewood perceived as a problem several behavioural trends of the working class people in the 1960's - in particular, they had become passive consumers of mass culture, and most were politically inactive (Holdsworth, 2011; Littlewood, 2003; Mathews, 2007a). They indulged in entertainment genres that allowed them to forget about their daily problems, 
to exercise as little intellectual effort as possible, and to engage in commonplace fun. Even worse, Littlewood saw many working class people, who were psychologically crushed and morally defeated, and who often found consolation and support in the tabloid publications or the local pub. These people rarely had motivation to go and experience an art exhibition or a theatre play (Holdsworth, 2011; Littlewood, 2003; Mathews, 2007a).

The story of the Fun Palace says quite a bit about the importance of problem formulation. Theoretically speaking, this happened in several stages or steps. Led by her distinctive professional perspectives and vision as a theatre director, Joan Littlewood spontaneously came up with a particular idea about the problem. When she co-opted Cedric Price, an architect, into collaborating with her, he initiated a revision and reformulation of the problem. Philosophically, he saw the social situation similarly to the way Littlewood did, albeit differently due to his architectural background. His design education led him to question and critique clients' requests and ideas about what they needed, and to reconceptualise them and propose a new vision (Littlewood, 2003, p. 628; Mathews, 2007a).

Littlewood envisioned theatre as an instrument for empowering the masses and teaching them to think critically and creatively. She looked at art as an instrument for transforming society in a positive way, making people more self-aware, active, compassionate, and humane. She also believed that learning and personal development were core functions of theatre (Holdsworth, 2011; Mathews, 2007a).

Our intent here is to demonstrate the social nature of analysis and problematization. We bring this moment as an example how a non-sociologist, a citizen activist, has perceived the social situation and has conceptualized a social way to alleviate the. It is into this is a niche where sociologists can bring their knowledge and professional methods to formulate the problem in a systematic way. However, as the niche was open at the time, the theatre director and social activist filled the void. We can only speculate what would have happened if professional sociologists have taken on this task and how they would have formulated the problem.

\section{Generating the Social Concept}

When considering the social situation and the problem, Joan Littlewood considered an interactive theatre that would engage people to think and even to take part in the performances. She wanted the audience to be stimulated intellectually so people would reflect on their lives and daily problems, look critically at society and their position in it, and learn and grow personally. Her philosophy of theatre led to experiments with audience participation, and for that purpose, she needed a completely new type of theatre building that could encourage and support increased participation by the audience. She also wanted to keep the fun and entertaining nature of the theatre institution, including the spontaneity and immediacy of the experience, its humanistic contributions, and its aesthetic nature. Her concept was innovative and experimental, and yet it was still a theatre project. She surveyed all existing theatre buildings at that time, didn't find any that would suit her needs, and decided she needed a brand new building that would support her mission and theatre experiments.

When Cedric Price came on board, he was fascinated by Littlewood's vision and goals for a new kind of theatre. He was energized by her idea of empowering the working class through exploration and self-education, of fostering meaningful life by infusing pleasurable and entertaining components in all activities, and of preparing people for re-entry into the job market. He encouraged her to expand the boundaries of her project and transform it into a new endeavour of a much larger scale (Mathews, 2007a). Price encouraged Littlewood to work on her ideas about the intellectual development of the people and to rethink the project in that 
direction. For a long time, Price and Littlewood were unable to categorize this new building project. It didn't fit neatly in any one of the existing organizational and building typologies.

In brief, the new facility was intended to serve working class people-for educating and re-educating them, and for creating skills for individual inquiry and life-long learning. These goals would have to be done democratically, without applying pressure and telling people what to do. In order to motivate citizens, each activity would be designed to involve entertaining moments and to provide amusement and personal fulfilment. People would be offered opportunities to learn in a pleasurable and relaxing environment, at their own pace. Fun and free choices of activities were envisaged as forces to generate interest and motivation. Littlewood and Price intended to expand and refine these ideas in numerous meetings over the span of several years.

The Fun Palace was a project without a precedent. It was a design for a new social organization and an institution conceived in response to a particular social situation. Littlewood's ideas about infusing professional theatre with audience participation and collaboration led to the conceptualization of an unconventional theatre phenomenon. Cedric Price grasped this idea and very quickly expanded it to include many of Littlewood's more implicit social visions.

However, the clarification and specific details of the idea still had a long way to go. At the beginning, the initiators deliberated over several metaphoric images for the project, including "university of the streets," "laboratory of fun," "laboratory of pleasure," (Price and Littlewood, 1968), 24/7 community centre, people's palace, and others (Holdsworth, 2011; Mathews, 2007a, p. 67). After Price's proposal "Fun Palace" was accepted, the project transcended the private realm of Littlewood to become a real cooperative effort, for all practical purposes led by the architect, Cedric Price.

We would like to emphasize here that the development of the social concept of the project is a very important act because it will later shape the social organization and activity systems, as well as the ensuing architectural ideas and structures. Yet, the leading figures in this process were not sociologists, but rather people from other professions who relied on their encyclopaedic knowledge, their intellect, and sound logic. However, the nature of decision making and the necessary knowledge and skills suggest a job suited for sociologists, a professional niche that was waiting for them. And again, this case demonstrates that when there is a particular societal need that is not satisfied by a particular profession, there are always people who will fill the gap and engage with the problem.

\subsection{Developing the Social Concept: Organizing Activity Systems}

As the vision of Fun Palace became more concrete, it was further envisaged as multifunctional place that would offer a wide array of activities. Its mission was to foster exploration, learning, intellectual development, and personal growth. Therefore, the corresponding activities needed a relaxed and enjoyable atmosphere, fusing achievement and fun. The designers emphasized the personal choice of activities and the option for participants to enter and exit the process at any time. Every visitor would be tacitly encouraged, but not pressured, to participate, to explore, and to create. This approach intended to fuse leisurely activities, amusement, and entertainment with education and critical thinking, as well as observation and participation in a multitude of areas. People were expected to survey different activities, select an area of participation, and engage at their own pace. The plan was that participants would learn new skills without fear of failure. In later visions of the facility, Littlewood also contemplated the idea of one-stop shopping and provisions for daily needs like on-site laundry, car services, and catering services (Holdsworth, 2011, p. 217).

By this time, project volunteers had been organized into several committees and 
teams. On the basis of the visioning process, the committees started generating and discussing a wide range of activities to be included in the project. The variety of professions and disciplines represented on the teams led to very different approaches. Some committees were simply brainstorming. Others, like the Cybernetics Committee, used scientific methods and procedures. Guided by the general project philosophy, committee members contemplated not only what activities were necessary for attaining project goals, but also how these activities would be performed and what behaviour patterns would be fostered.

The general activity groups were described in terms of functional zones (Mathews, 2007a, p. 275): Zone 1: teaching machines; Zone 2: new forms of expression (performance arts); Zone 3: films and lectures; Zone 4: scientific experiments; Zone 5: painting and sculpture; and Zone 6: music. Psychologist John Clark, chair of the Ideas Committee, developed a list of about 70 activity topics (Mathews 2007a, p. 116, p. 274). Some examples included the Tower of Dancing Light, the Flying Men, the Bubbling Wall, the Sensitive Speedway, the Art-Machine, the Tactful Tango Teacher, the Ladies of Fashion, the CounterPoint Computer, the Palace of Illusions, Captain Nemo's Cabin, the Fiery Pagoda, the Scholarly Staircase, the Cybernetic Cinema, Professor Piaget's Pavilion, the Tower of Babel, and many more. Despite a number of shortcomings, the very fact of engaging in such activity design indicates countless opportunities for social scientists. It is to consider what kind of a product we would have witnessed had sociologists taken the lead and used their knowledge and skills for the activity design.

Documents and publications on Fun Palace indicate that committee members were working not only on activity clusters and individual activities, but also on the ways these activities would be performed. In line with the project philosophy and the general concept, they envisaged a complex environment which, though inclusion and democratic participation, could provide participants freedom to choose from wide variety of activities in a pleasurable, fun, relaxed atmosphere while at the same time developing strong motivation for active participation due to incentives for engagement (Holdsworth, 2011; Mathews, 2007a; Price and Littlewood, 1968). The project emphasized the importance of fun, joy, and pleasure, a leisurely atmosphere, and freedom of choice. These were important considerations that affected greatly the design and format of activities, activity needs, and behaviour patterns.

Below, we show in more detail the organization of several activity systems and clusters. In her presentation of the project in the early 1960's, Littlewood began her description of activities with the "fun arcade" (Littlewood, 1964; Price and Littlewood, 1968). This functional cluster was intended for games and subject tests. The prominent theatre director envisaged them as being similar to the ones designed by psychologists and electronic engineers for various industries. The Palace also offered a music area. By day, it was intended to serve as an open music school that provided instruments, instruction, recordings, and other facilities in a wide array of music genres. By night, the designers envisaged music performances: jam sessions, jazz festivals, and dance.

The "science playground" was planned for lectures and lab demonstrations. They were going to be supported by closed-circuit television showing educational films and working models to illustrate the lectures. By night, the space would be used for a related, yet different, group of activities. People would have opportunities to engage in serious discussions in philosophy, science, poetry, and other intellectual domains. They would also enjoy good company and refreshments, and would engage in discussions until dawn.

The theatre (acting) activities were envisaged with at least three different objectives. One objective was to provide drama therapy for working class people. Another was to use the drama for enhancing political awareness, developing critical thinking, analyzing everyday life, finding new opportunities, and liberating oneself from fears and taboos. Still another objective 
was the more conventional pursuit of mastery in acting, performance explorations, and impromptu participation. The theatre cluster of activities was a direct outgrowth of the avantgarde performance philosophy of Littlewood.

Some authors (Holdsworth, 2011, p. 216) discuss the amateurish interpretation of drama therapy and the lack of consideration for potential side effects when used by occasional participants. This criticism can also apply to a number of other activity clusters. Although they were innovative and feasible in principle, and although they were developed by intellectuals and social scientists, there should have been a number of concerns about their actual contributions and potential side effects. Sometimes the committees were overenthusiastic and tended to engage in brainstorming rather than in systematically advancing towards solutions.

In summary, the work on the Fun Palace project was tantamount to social design. The process started with analyzing the social situation. After that it continued with problematizing the social situation - that is, formulating a problem area in terms of societal needs and project objectives. Then the team developed a general concept of a new social institution and organization with their mission and objectives. The concept was developed further into activity systems that would work to meet those objectives.

\section{Some Reflections on the Work of Non-Sociologists and the Niche for Sociologists}

The Fun Palace project was ahead of its time. It was so innovative that both the general public and the city officials had difficulties appreciating it. The architectural project could not gain approval by the city authorities, could not get a construction site, and had no prospects for real funding. Therefore, the architectural project was closed in its very early stages. However, the social design aspect of the Fun Palace was completed to a level that provides a good example of the nature and scope of social design engagement within the process of facilities planning.

However, because many of the major participants didn't have any sociological background, they could not foresee the social implications of their design decisions despite their humanistic objectives. We don't present this as a critique; our goal is to show sociologists what people do in such cases, how they do it, and what the consequences can be. Our intent is to encourage sociologists to actively pursue involvement in such projects, as well as to see that there is nothing esoteric in the process. In fact, this is their playing field, their area of expertise.

For example, Gordon Pask and the Cybernetic Committee engaged in an in-depth design of Fun Palace activities, and they detailed at length their objective of creating feedback and control loops for automatic management of building functions. Pask's proposal for a wide-range collection of information about all building users, their choices, and behaviours made Littlewood quite uneasy (Holdsworth, 2011). Although Pask had only the best intentions of creating a self-managed building system based on user demand and actual behaviours, he went quite close to total control of the Orwellian type. Here one more time we can question what would have happened if this process had been led by a sociologist rather than a cyberneticist who was so obsessed with the new technology that he might have overlooked some basic aspects of social life.

Some critics (Holdsworth, 2011) debated whether Littlewood had also crossed a line with her desire to shape people in a particular way. They pointed to her connections with an ideology that was insistent on designing peoples' lives, referring to her strong relationships with the Stalinist regime in the Soviet Union. This problem deserves further discussion, as there are ways to alleviate it and keep social design democratic and transparent. Such 
problems emerge when non-sociologists engage in social design lead by ideology and general humanistic visions rather than by social science knowledge and methods.

It is amazing that a cyberneticist, (although a great one, Gordon Pask) went much more aggressively into social design than the social scientists. He also encouraged the architect Cedric Price to be more proactive and take more responsibility in the social design phases. Pask referred several times to the work of the architects as social engineering (Holdsworth, 2011; Mathews, 2007a). Cyberniticians and architects have a tradition of envisaging new configurations, changing existing situations, and looking at the world as an arena for design. Here the phenomenon of the two cultures (Snow, 1959) obtains a new dimension, which we may refer to as the Third Culture. Actually, if we look at the attitudes towards changing the World, the paradigmatic divisions between natural sciences and humanities are less pronounced (despite their huge differences) than the division between science and design. Today, design is well accepted as a culture of its own, aiming at change and transformation of current situations and envisaging future states and outcomes.

The work and outcomes of the Fun Palace committees demonstrate astonishing spontaneity and serendipity in the process. One might expect that they would have employed a more systematic approach that would have brought in the rigor of scholarly methodology and field research design. The brainstorming process and the list of 70 activities developed by the Ideas Committee clearly illustrates their creative approach, which evidently didn't go much further than brainstorming. The chair of the committee was a psychologist (John Clark). It is also interesting to note that the people who most systematically envisaged the social organism of the Fun Palace were Cedric Price (an architect) and Joan Littlewood (a theatre director) rather than the few social scientists on the team. In the Fun Palace case, Joan Littlewood and Cedric Price took the lead over sociologists, anthropologists, and psychologists.

There is an explanation for this. People like Littlewood who are engaged actively in their field are in an advantageous position to problematize and to formulate problems and solutions. However, considering the vast topic that Littlewood tackled, encompassing the major aspects of 1960's Great Britain, it is still astonishing that professional sociologists didn't take the initiative and engage with these issues much earlier. In fact, besides Littlewood, at that time in Great Britain, there were several other groups of intellectuals that envisaged such problems in society, but none of the leaders of these groups were career sociologists. Our hunch is that sociologists were preoccupied with research and publishing rather than designing new social realities. We can speculate that academic traditions and attitudes limit the range of professional engagements and preclude innovation.

There is another aspect to consider. After Littlewood developed her concept for a new kind of theatre and determined that she needed a new building, she contacted an architect. In the public consciousness, when people need a building, they quickly envisage an architect as the prime provider. The Fun Palace demonstrates that between a need for a new building and the employment of an architectural service, there is place and there is a necessity for the design of the social entity that will inhabit the building. This presupposes the need for experts that will engage in social design. However, there are no institutionalized providers of social design, and society doesn't feel a need for such a profession. One reason that Littlewood did not search for a sociologist to develop her idea is that in society, sociologists are perceived as scientists who teach and write, rather than designers of social organizations that need building accommodation. On the other end of the spectrum, architects aggressively pursue building commissions. Every time they hear about a building project, they aggressively offer their services to resolve all of the client's problems - all, including the social problems.

It is true that within the domains of hospital planning and correctional facilities planning, the organizational design and social innovation component has progressed 
tremendously. Still, even there, the process structure is developed by management consultants and industrial engineers, thus influencing the social design aspects of the project with their educational background. We can only imagine the benefits for society, when sociologists are included in the planning phases of such projects.

\section{Concluding Remarks}

In this paper, we have highlighted the social and sociological nature of the project engagements and activities in the planning and pre-design phases in architecture. We show how these activities are appropriated and performed by non-sociologists, ranging from architects to artists to cyberneticists and to many other professions. The case we analyze demonstrates a necessity for improving and professionalizing these activities and creating a new profession of social design. We also send a message that social design is ubiquitous, it is all around us, and it carries immense opportunities for sociologists.

The Fun Palace project was steered and dominated by non-sociologists because there were no institutionalized structures to support social design engagements. At that time, and even up to now, there is no institutionalized social design profession with its professional organization, educational programs, research associations, conventions and conferences, publication and information outlets, and all other traits pertaining to the definition of a profession.

By analyzing the nature of activities in the planning and pre-design process, we make a case that although there is no explicitly formulated societal need, there is a niche for professional social designers. This niche is delineated by the nature of activities and the type of decision making undertaken by the project participants. Our future mission is to work on explicating and formulating this societal need so that there is appreciation of its importance and motivation to create a profession that is fully equipped to deal with social design problems and projects. This is a necessary step toward institutionalizing social design as a profession and recognizing sociologists as the prime agents of this profession and prime candidates for such projects.

We hope that the analysis and discussion of the project activities and decision making processes will help sociologists see new fields for professional actualization. Our personal experience shows that many sociologists hesitate to take on practical projects because they are categorized in the realms of other professions and because the project delivery process looks esoteric and distant. With this paper, we want to send a message that social design is right in the ball park of sociology, and sociologists can do it much better than the other professions. "Sociological social design affords designers a critical stance and investigation of the presently pertaining social relations, allowing a more explicit critique than that of molecular design and a more theoretically grounded position than utopian design." (Koskinen \& Hush, 2016, p. 68). Therefore, sociologists should take the leadership in such endeavours and guide the process with their knowledge and skills.

For that purpose, sociologists might need to retool. They will have to acquire additional knowledge and skills for project action. Sociological education should go over and beyond research courses to train sociologists in project process, practical problem solving, and project management. However, sociologists are in a unique position with their strong background in social theory and research methods. From here it is only one step away to add the design process knowledge and design problem solving skills. At a time when all academic disciplines are struggling and fighting for job placement of their graduates, this will be a major breakthrough in empowering the sociological profession.

Sociologists have remarkable presence at a macro scale, addressing major social 
problems. However, they often shy away from the micro scale, the domain of everyday life events. It is true that at macro-scale sociology can make a much bigger impact on our social reality and change it for the better. Yet, at the same time, the micro-scale situations occur by the thousands, and producing impact in each one of them would gradually transform the world.

Also, the experience and skills acquired by working at the micro level will help the implementation of big ideas in a new way, and this is both practical and feasible. The design experience gained while working with a local community to develop a new centre can be transferred to other fields. Working jointly with other professions will develop new knowledge and skills, such as project management, design process organization, and research utilization, among others. The design attitude and approach learned in such projects will enhance the creative potential of sociologists in other domains of social intervention as well. Such experiences might make sociologists more courageous, more pragmatic, and more active in search of projects and fields of application.

Thus, sociologists should take a more proactive position regarding the design of organizations and institutions. Currently, organizational design has positioned itself in the field of management as a discipline that aims toward change and transformation. It has developed a well-organized process and robust design methodology. It is applied mostly in a business context and focuses exclusively on business issues. Sociologists can bring a holistic, socially responsible perspective to such organizational design. Also, because organizational designers are not motivated to engage in civic projects, there is a void in that domain because civic projects require content knowledge that is different from the knowledge required in business and management. However, there are projects on organizations and programs in the field of leisure and entertainment, intellectual growth and advancement, community and cultural centres, and many others in this domain.

Sociologists have a lot to contribute in these fields. With the help of the sociological imagination (Mills, 1959), all of these projects can become prime examples of social design. Our sociological community can facilitate change in various ways, from programs on poverty and inequality, to drug addiction and crime, to urban development and community building, and to the development of the spatial-material infrastructure of such programs. Designing social institutions and organization and planning the activity systems of civic buildings are significant contributions to cities and communities, and will enhance the quality of life of millions of people and benefit the welfare of society. Such projects, with input from sociologists, will then build upon each other and support societal efforts to alleviate social problems.

\section{References}

Armstrong, L., Bailey, J., Julier, G. \& Kimbell, L. (2014). Social design futures: HEI research and the AHRC. University of Brighton. Retrieved June 14, 2017, from http://eprints.brighton.ac.uk/13364/1/SocialDesign-Report.pdf.

Boguslaw, R. (1971). The design perspective in sociology. InW. Bell \& J. Mau (Eds.), The Sociology of the Future (pp.240-258). New York: Russell Sage Foundation.

Carey, J. (Ed.). (2000). The Faber book of utopias. London: Faber and Faber.

Chaiklin, S., Hedegaard, M., \&Jensen, U. (Eds.). (1999). Activity theory and social practice: Cultural-historical approaches. Aarhus, DK: Aarhus University Press.

Durkheim, E. (1960). The elementary forms of religious life. Paris: Presses Universitaires de France. (Original work published 1912)

Engeström, Y., Miettinen, R., \&Punamäki, R. (1999). Perspectives on activity theory. Cambridge: Cambridge University Press.

Holdsworth, N. (2011). Joan Littlewood's theatre. Cambridge: Cambridge University Press. 
Koskinen, I., \& Hush, G. (2016). Utopian, molecular and sociological social design. International Journal of Design 10(1), 65-71.

Lektorsky, V. (Ed.). (1990). Activity: Theories, methodology \& problems. Orlando, FL: Paul Deutsch Press, Inc. Leont'ev, A. N. (1978). Activity, consciousness, and personality. Englewood Cliffs, NJ: Prentice-Hall.

Littlewood, J. (1964). A laboratory of fun. New Scientists 22(14), 432-433.

Littlewood, J. (1994). Joan's book: The autobiography of Joan Littlewood. London: Methuen.

Lobsinger, M. (2000). Cybernetic theory and the architecture of performance. In S. W. Goldhagen \& R. Legault (Eds.). Anxious modernism (pp. 119-139). Montreal and Cambridge, MA: Canadian Centre for Architecture and Massachusetts Institute of Technology.

Kaptelinin, V., \&Nardi, B. A. (2006). Acting with technology: Activity theory and interaction design. Cambridge, MA: MIT Press.

Mathews, S. (2007a). From agit-prop to free space: The architecture of Cedric Price. London: Black Dog Publishing.

Mathews, S. (2007b). Cedric Price as anti-architect. In T. Anstey, K. Grillner \& R. Hughes (Eds.). Architecture and Authorship (pp. 142-147). London: Black Dog Publishing.

Mills, C. W. (1959). The Sociological imagination. London: Oxford University Press.

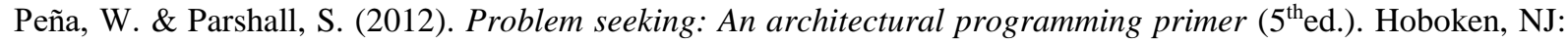
John Wiley \& Sons.

Price, C. (2003). Cedric Price: The square book. London: Academy Editions; Chichester: John Wiley.

Price, C. \& Littlewood, J. (1968). The Fun Palace. The Drama Review: TDR, Architecture/Environment, 12(3) 127-134.

Rawls, A. W. (2004). Epistemology and Practice: Durkheim's The Elementary Forms of Religious Life. Cambridge: Cambridge University Press.

Snow, C. P. (1959). The two cultures and the scientific revolution. Cambridge: Cambridge University Press.

Wiener, M. (1981). English culture and the decline of the industrial spirit, 1850-1980. Cambridge: Cambridge University Press. 